\title{
Differentiation of Domains in Composite Surface Structures by Charge-Contrast X-ray Photoelectron Spectroscopy
}

\author{
Sefik Suzer, ${ }^{*, \dagger}$ Aykutlu Dâna, ${ }^{\ddagger}$ and Gulay Ertas ${ }^{\dagger}$ \\ Chemistry Department and Physics Department, Bilkent University, 06800 Ankara, Turkey
}

An external bias is applied to two samples containing composite surface structures, while recording an XPS spectrum. Altering the polarity of the bias affects the extent of differential charging in domains that are chemically or electronically different to create a charge contrast. By utilizing this charge contrast, we show that two distinct silicon nitride and silicon oxynitride domains are present in one of the composite samples. Similarly, we use this technique to show that titanium oxide and silicon oxide domains exist as separate chemical entities in another composite sample.

X-ray photoelectron spectroscopy (XPS) is a powerful analytical technique for characterizing different chemical/physical forms of elements within the top $0-10$-nm surface layers. ${ }^{1}$ In principle, determination of the chemical state of an element in a homogeneous surface is straightforward. However, in practical analysis, one is faced with having to analyze a number of composite materials that are heterogeneous from the viewpoint of microstructure, chemical composition, or both. In general, a specimen for XPS analysis should be conductive, and in the case of composite materials, the electronic conductivity may not be uniform and differential charging may develop as a result of photoemission from insulating components. Although several techniques have been developed to minimize the charging, complete elimination is not always possible. ${ }^{2}$ The positive charging is usually compensated by directed flow of low-energy electrons from an external unit (flood gun) to the sample, which under certain circumstances, overneutralizes it and may even cause negative charging.

Purposely generated negative charging, called controlled surface charging (CSC), has been successfully used for deriving some chemical/physical properties of various surface structures. ${ }^{3-7}$ Lau and co-workers have utilized the CSC to extract structural and electrical properties ofultrathin dielectrics on semiconductors. ${ }^{8-11}$

\footnotetext{
* Towhom correspondenceshould beaddressed.E-mail: suzer@fen.bilkent.edu.tr. $\dagger$ Chemistry Department.

\# Physics Department.

(1) Briggs, D.; Seah, M. P. Practical surface analysis. Part I. Auger and X-ray photoelectron spectroscopy, 2 nd ed.; John Wiley \& Sons Ltd.: London, England, 1996.

(2) Cazaux, J. J. Electron Spectrosc. Relat. Phenom. 2000, 113, 15-33.

(3) Sherwood, P. M. A. Surf. Sci. 2006, 600, 771-772.

(4) Lau, W. M.; Wu, X. W. Surf. Sci. 1991, 245, 345-352.

(5) Lau, W. M. J. Appl. Phys. 1989, 65, 2047-2052.
}

Thomas et al. ${ }^{12}$ were able to separate the surface spectrum (mainly silicon dioxide) from the silicon substrate spectrum (consisting of contamination and silicon dioxide on silicon), by use of surface charging, and similar applications were also reported by Ermolieff et al. ${ }^{13}$ and Bell and Joubert, ${ }^{14}$ while Miller et al. applied the technique to separate the XPS signals of the fiber from the exposed matrix at fractured surfaces. ${ }^{15}$ Surface charging was also utilized for lateral differentiation of mesoscopic layers and for depth profiling. 6,7 One interesting application of the surface charging for composite surface structures was reported by Ohno et al. ${ }^{16}$ for separate examination of the chemical nature of the carbon fibers and the BMI resin, which enabled them to resolve the carbon fiber and the resin phases in one specimen.

In all of these studies, surface charging was controlled or varied via a low-energy electron flood gun, whereas, as we attempt to demonstrate in the present contribution, useful information can also be extracted by analysis of the positively charged surfaces. We control or enhance the positive charging by applying an external bias to the sample rod while recording the spectrum, similar to what has been reported by others. ${ }^{17-21}$ We were able

(6) Shabtai, K.; Rubinstein, I.; Cohen, S. R.; Cohen, H. J. Am. Chem. Soc. 2000, $122,4959-4962$

(7) Doron-Mor, H.; Hatzor, A.; Vaskevich, A.; van der Boom-Moav, T.; Shanzer, A.; Rubinstein, I.; Cohen, H. Nature 2000, 406, 382-385.

(8) Lau, W. M. Appl. Phys. Lett. 1989, 54, 338-340.

(9) Chan, R. W. M.; Kwok, R. W. M.; Lau, W. M.; Yan, H.; Wong, S. P. J. Vac. Sci. Technol., A 1997, 15, 2787-2792.

(10) Chan, R. W. M.; Kwok, R. W. M.; Lau, W. M. J. Appl. Phys. 1996, 79, 36353639 .

(11) Lau, W. M.; Jin, S.; Wu, X.-W.; Ingrey, S. J. Vac. Sci. Technol., B 1990, 8, 848-855.

(12) Thomas, J. H., III; Bryson, C. E., III; Pampalone, T. R. J. Vac. Sci. Technol., $B$ 1988, 6, 1081-1086.

(13) Ermolieff, A.; Deleonibus, S.; Marthon, S.; Blanchard, B.; Piaguet, J. J. Electron Spectrosc. Relat. Phenom. 1994, 67, 409-416.

(14) Bell, F. H.; Joubert, O. J. Vac. Sci. Technol., B 1997, 15, 88-97.

(15) Miller, J. D.; Harris, W. C.; Zajac, W. G. Surf. Interface Anal. 1993, 20, 977-983.

(16) Ohno, S.; Lee, M. H.; Lin, K. Y.; Ohuchi, F. S. J. Vac. Sci. Technol., A 2001, 19, 1116-1120.

(17) Gouzman, I.; Dubey, M.; Carolus, M. D.; Schwartz, J.; Bernasek, S. L. Surf. Sci. 2006, 600, 773-781.

(18) Dubey, M.; Gouzman, I.; Bernasek, S. L.; Schwartz, J. Langmuir 2006, 22, $4649-4653$.

(19) Johansson, G.; Hedman, J.; Berndtsson, A.; Klasson, M.; Nilsson, R. J. Electron Spectrosc. Relat. Phenom. 1973, 2, 295-317.

(20) Dickinson, T.; Povey, A. F.; Sherwood, P. M. A. J. Electron Spectrosc. Relat. Phenom. 1973, 2, 441-447.

(21) Havercroft, N. J.; Sherwood, P. M. A. Surf. Interface Anal. 2000, 29, 232240 .

Analytical Chemistry, Vol. 79, No. 1, January 1, 2007

183 

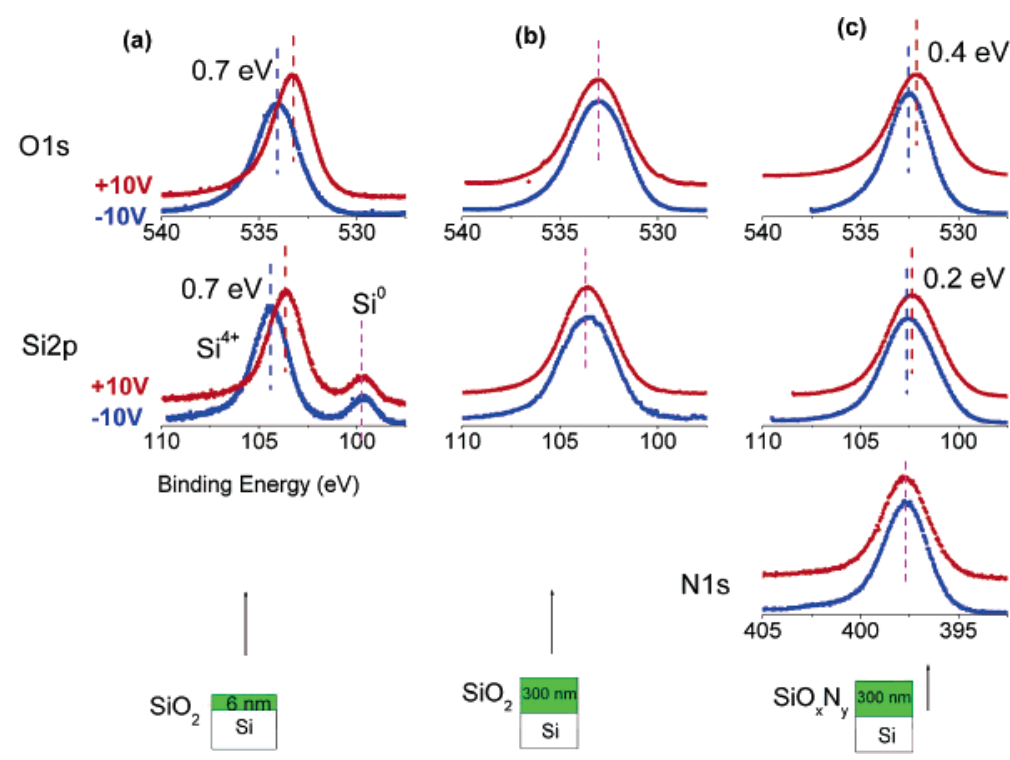

N1s

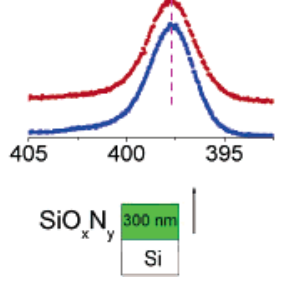

Figure 1. Si $2 p, O 1 s$, and $N$ 1s regions under +10 and $-10 \mathrm{~V}$ dc bias for $\mathrm{SiO}_{2}$ samples, one of them containing $\sim 6$-nm and the other $\sim 300$-nm oxide layer together with a $\sim 300$-nm composite siliconoxynitride sample.

to apply this simple method (i) to analyze some dielectrical properties of ultrathin silicon oxide layers, (ii) to separate otherwise overlapping XPS peaks of the same atom belonging to different chemical entities, and (iii) to derive information related to the proximity of the atoms within composite multilayers. ${ }^{22-24}$ We now extend our application to detect the presence of domains that are chemically or electronically different in different composite surface structures. For the first application, analysis of an annealed silicon oxynitride sample is presented, and for the second one, a sample containing both silicon oxide and titanium oxide is presented.

Silicon nitride has received a great deal of attention due to its superior mechanical and electrical properties for applications in microelectronics and optoelectronics. Some of these properties include better breakdown strength, higher electrical permittivity, improved barrier to impurity diffusion, and superior resistance to plasma and radiation damage ${ }^{25-29}$ However, most preparation routes produce oxynitrides rather than the pure nitride. Then, the question arises as to whether oxides and nitrides are separate entities or domains, especially after thermal annealing. Distinguishing the various chemical domains present in a given sample is an analytical challenge, and partial success has been achieved by IR spectroscopy. ${ }^{30,31}$ In both XPS and IR techniques, an average structure of the sample examined is determined, and the pres-

(22) Ulgut, B.; Suzer, S. J. Phys. Chem. B 2003, 107, 2939-2943.

(23) Suzer, S. Anal. Chem. 2003, 75, 7026-7029.

(24) Karadas, F.; Ertas, G.; Suzer, S. J. Phys. Chem. B 2004, 108, 1515-1518.

(25) Chaiyasena, I. A.; Lenahan, P. M.; Dunn, G. J. Appl. Phys. Lett. 1991, 58, $2141-2143$.

(26) Bustillo, J.; Chang, C.; Haddad, S.; Wang, A. Appl. Phys. Lett. 1991, 58, $1872-1874$.

(27) Dunn, G. J. J. Appl. Phys. 1989, 65, 4879-4883.

(28) Dunn, G. J. Appl. Phys. Lett. 1988, 53, 1650-1651.

(29) Yount, J. T.; Lenahan, P. M.; Krick, J. T. J. Appl. Phys. 1994, 76, 17541758.

(30) Hernandez, M. J.; Garrido, J.; Martinez, J.; Piqueras, J. Semicond. Sci. Technol. 1997, 12, 927-932.

(31) Zhang, B. R.; Yu, Z.; Collins, G. J.; Hwang, T.; Ritchie, W. H. J. Vac. Sci. Technol., A 1989, 7, 176-188. ence/absence of domains with different chemical compositions cannot be verified easily. Due to the predominantly amorphous nature of the oxynitride structures, diffraction techniques cannot be of help either.

Titanium and silicon mixed oxides are encountered in various catalytical and photocatalytical applications, antireflection coatings, filters, mirrors, etc.; and similar questions related to domains are also of importance. ${ }^{32-36}$ For some coating applications, control of the refractive index is the most crucial issue, and two approaches have been used in order to get intermediate refractive indices: (i) use mixed oxides with a high and low index material, $, 37,38$ and (ii) stack very thin layers of pure materials to achieve any index profile. ${ }^{39}$ These two methods require good control of the formation of mixed material or of interfaces, and it is important to know how the interfaces are formed. Using a combination of XPS and FT-IR techniques, the formation of $\mathrm{Si}-\mathrm{O}-\mathrm{Ti}$ bond or $\mathrm{SiO}_{2} / \mathrm{TiO}_{2}$ in a single phase material depending on the Ti content in the mixture was claimed by different groups. ${ }^{33,38,40,41}$ In all these studies, separate phases were only identified by the behavior of the $\mathrm{O}$ 1s core level peak to indicate that at least two phases coexist. The appearance of an extra shoulder in the 0 1s spectra of the

(32) Gracia, F.; Holgado, J. P.; Caballero, A.; Gonzalez-Elipe, A. R. J. Phys. Chem. B 2004, 108, 17466-17476.

(33) Gracia, F.; Yubero, F.; Espinos, J. P.; Holgado, J. P.; Gonzalez-Elipe, A. R.; Girardeau, T. Surf. Interface Anal. 2006, 38, 752-756.

(34) Mergel, D.; Buschendorfa, D.; Eggerta, S.; Grammesb, R.; Samsetc, B. Thin Solid Films 2000, 371, 218-224.

(35) Gracia, F.; Holgada, J. P.; Gonzalez-Elipe, A. R. Langmuir 2004, 20, 1688 1697.

(36) Abad, J.; Rogero, C.; Mendez, J.; Lopez, M. F.; Martin-Gago, J. A.; Roman, E. Appl. Surf. Sci. 2004, 234, 497-502.

(37) Demiryont, H. Appl. Opt. 1985, 24, 2647-2650.

(38) Gallas, B.; Brunet-Bruneau, A.; Fisson, S.; Vuye, G.; Rivory, J. J. Appl. Phys. 2002, 92, 1922-1928.

(39) Gluck, N. S.; Sankur, H.; Heuer, J.; DeNatale, J.; Gunning, W. J. J. Appl. Phys. 1991, 69, 3037-3045.

(40) Lassaletta, G.; Fernandez, A.; Espinos, J. P.; Gonzalezelipe, A. R. J. Phys. Chem. 1995, 99, 1484-1490.

(41) Larouche, S.; Szymanowski, H.; Klemberg-Sapieha, J. E.; Martinu, L.; Gujrathi, S. C. J. Vac. Sci. Technol., A 2004, 22, 1200-1207. 


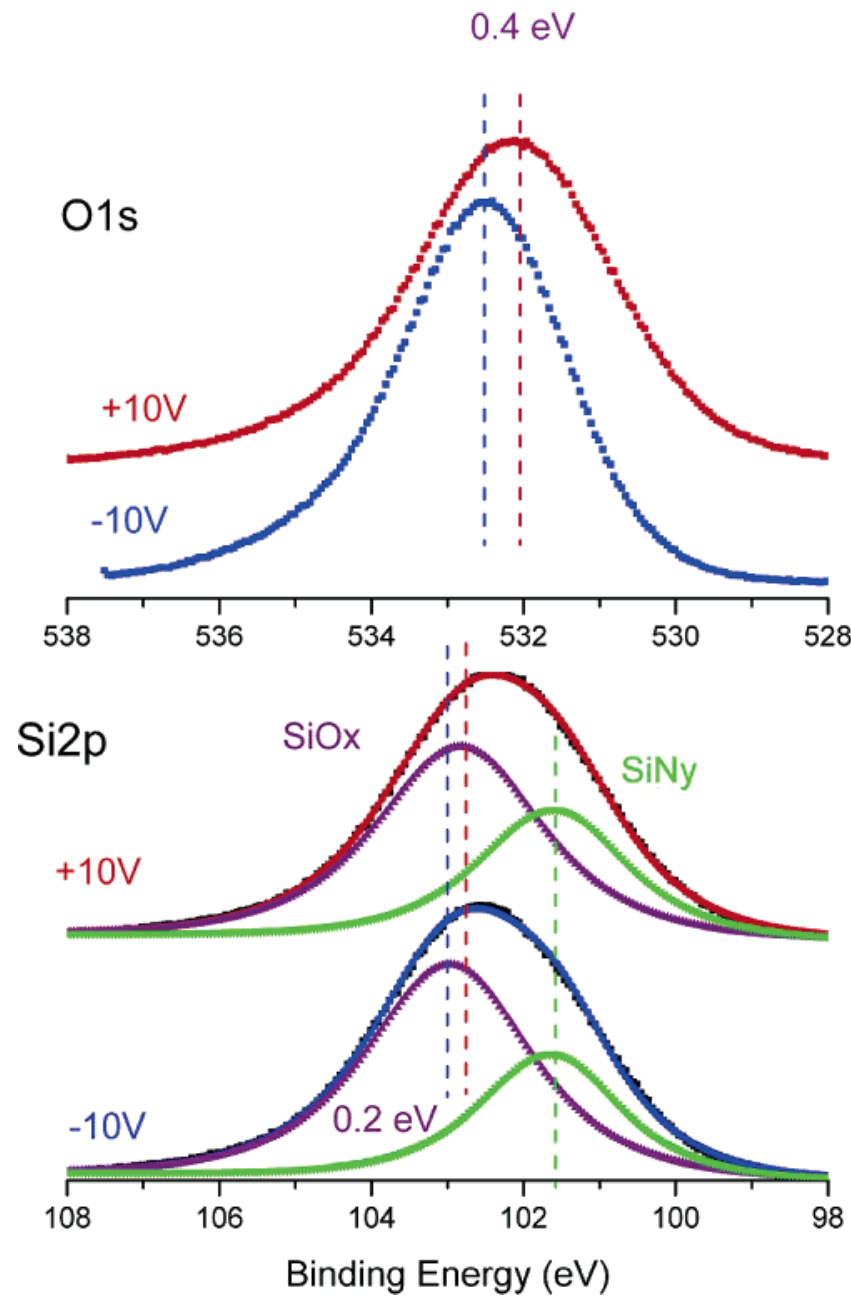

Figure 2. Si $2 p$ and $O 1$ s regions of XPS spectrum of composite siliconoxynitride sample upon annealing at $1100{ }^{\circ} \mathrm{C}$ with +10 and $-10 \mathrm{~V}$ external dc biases applied to the sample rod.

samples with intermediate compositions was accepted as evidence for the presence of $\mathrm{SiO}_{2}$ and $\mathrm{TiO}_{2}$ as separate phases. ${ }^{33,42}$ The presence of $\mathrm{Si}-\mathrm{O}-\mathrm{Ti}$, confirming the presence of a single phase containing both $\mathrm{Si}$ and $\mathrm{Ti}$ was also claimed by FT-IR spectra of $\mathrm{SiO}_{2}, \mathrm{TiO}_{2}$, and mixtures. However, the FT-IR data do not provide enough evidence for the formation of a single phase or separate phases in these samples ${ }^{41}$ and none of the previous approaches can provide indisputable evidence about the presence or absence of different domains or phases. As we will demonstrate below, our method, by controlling the charging capacity of different components in composite films, provides a clear experimental tool for differentiation of domains that are chemically/electrically distinct.

\section{EXPERIMENTAL SECTION}

A Kratos ES300 electron spectrometer with Mg Ka X-rays (nonmonochromatic) was used for XPS measurements. In the standard geometry, the sample accepts X-rays at $45^{\circ}$ and emitted photoelectrons at $90^{\circ}$ with respect to its surface plane are analyzed. Samples were electrically connected to the sample holder, which was grounded or externally biased with a dc power supply.

(42) Brunet-Bruneau, A.; Fisson, S.; Gallas, B.; Vuye, G.; Rivory, J. Proc. SPIEInt. Soc. Opt. Eng. 1999, 3738, 188-196.

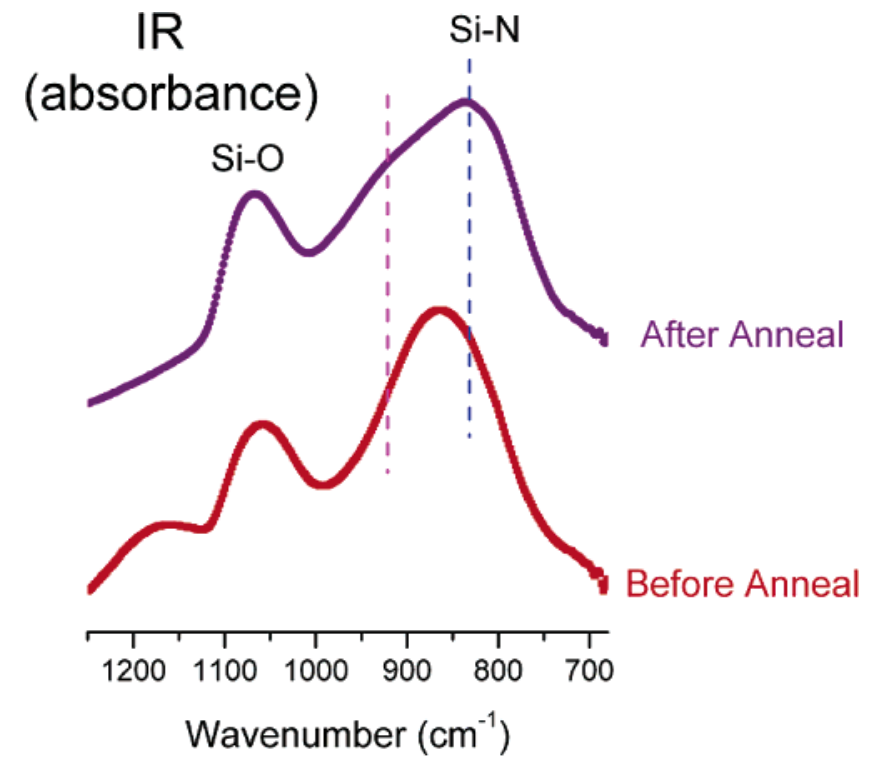

Figure 3. Part of the FT-IR spectra of the composite siliconoxynitride sample before and after annealing at $1100^{\circ} \mathrm{C}$.

Resolution of our spectrometer is slightly better than $0.80 \mathrm{eV}$ as measured in the $\mathrm{Ag} 3 \mathrm{~d}$ peaks. Since we extract binding energy differences by fitting the entire set of peaks, we estimate our error in measuring the binding energy differences to be better than $0.1 \mathrm{eV}$. FT-IR spectra of the samples were obtained using a Bruker Tensor FTIR system operating in the mid-infrared region, i.e., $400-4000 \mathrm{~cm}^{-1}$.

Silicon nitride films were deposited on p-type silicon wafer of orientation (100) using disilane ( $2 \%$ in nitrogen) and ammonia as reactant gases in a PECVD reactor (PlasmaLab 8510C) at a sample temperature of $350^{\circ} \mathrm{C}$ and a process pressure of 1000 mTorr under an applied rf power of $10 \mathrm{~W}$. Afterward, the samples were annealed in air at $1100{ }^{\circ} \mathrm{C}$ for $10 \mathrm{~min}$. The composite $\mathrm{SiO}_{x}+\mathrm{TiO}_{y}$ sample was obtained by depositing a thin layer of titanium onto a silicon substrate.

\section{RESULTS AND DISCUSSION}

As we have shown in our previous publications, the silicon oxide dielectric layer develops an overall positive charge which is reflected in the $\mathrm{Si} 2 \mathrm{p}, \mathrm{O}$ 1s, and $\mathrm{Si}_{\mathrm{KLL}}$ Auger peaks. This is best demonstrated in thin $(<10 \mathrm{~nm})$ oxide layers on a silicon wafer when both the silicon and silicon oxide $\mathrm{Si} 2 \mathrm{p}$ peaks are observable by XPS, and the measured binding energy difference between them exceeds the true chemical shift of $3.2 \mathrm{eV} .{ }^{1}$ We have also shown that the measured difference can be controlled by an external bias as reproduced again in Figure 1a for a sample containing $\sim 6$-nm thermal oxide layer. ${ }^{22,24}$ As can be gathered from the figure, the $\mathrm{Si}^{0}$ peak is not influenced by the bias but both the $\mathrm{Si}^{4+}$ and the $\mathrm{O} 1 \mathrm{~s}$ peaks are affected by as much as $0.7 \mathrm{eV}$ after altering the polarity of the bias. Under positive bias, more of the neutralizing low-energy electrons are attracted to the sample hence reducing the extent of the positive charge. For a thicker oxide sample, only the peaks of the oxide layer are accessible. As shown in Figure $1 b$, both the $\mathrm{Si} 2 \mathrm{p}$ and the $\mathrm{O}$ 1s peaks are broadened (due probably to enhanced charging), but again, both peaks display similar shifts under external bias as opposed to the case of the oxynitride sample of a comparable thickness as shown in 


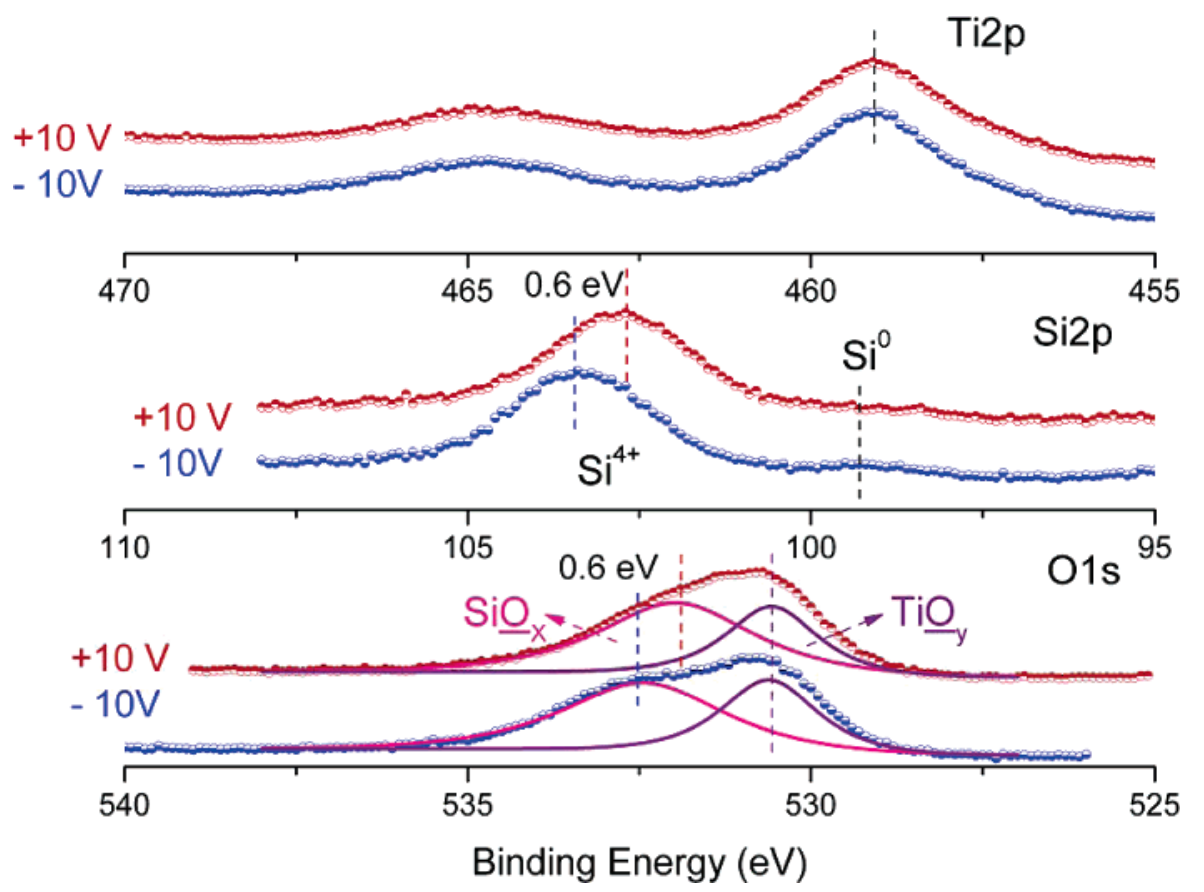

Figure 4. $\mathrm{Ti} 2 \mathrm{p}, \mathrm{Si} 2 \mathrm{p}$, and $\mathrm{O} 1 \mathrm{~s}$ regions of the XPS spectrum of a $\mathrm{TiO}_{2} / \mathrm{SiO}_{2}$ composite sample recorded while applying -10 and $+10 \mathrm{~V}$ external bias.

Figure 1c. Oxygen is present in all samples, but nitrogen is only present in the oxynitride sample and can be assigned to $\mathrm{N}^{3-} .{ }^{1} \mathrm{In}$ the oxynitride sample, we detect differences in the positions of both the $\mathrm{Si} 2 \mathrm{p}(0.2 \mathrm{eV})$ and the $\mathrm{O} 1 \mathrm{~s}(0.4 \mathrm{eV})$ peaks, and no difference can be detected in the $\mathrm{N}$ 1s peak position, after changing the polarity of the bias. We take this as a spectral signature of the presence of at least two chemically different domains. One of the domains is probably pure silicon nitride, since the $\mathrm{N}$ 1s corresponds to that of the $\mathrm{Si}_{3} \mathrm{~N}_{4}$. The other one cannot be assigned to pure oxide, since the shift in the $\mathrm{Si} 2 \mathrm{p}$ is only half of the shift in the $\mathrm{O} 1 \mathrm{~s}$. In order to gain more insight, we attempted to mathematically decompose the $\mathrm{Si} 2 \mathrm{p}$ peak into two components as shown in Figure 2: one belonging to pure nitride, and the other to the oxynitride to support our conclusion that these are the two chemically different domains (silicon nitride and silicon oxynitride). We should also stress that shifts observed in Figures 1 and 2 are measured only after the sample is annealed at $1100{ }^{\circ} \mathrm{C}$. The presence of different domains is also partially supported by FT-IR spectra of the silicon oxynitride film recorded before and after annealing as illustrated in Figure 3. Before annealing, the spectrum has a main absorption peaks around $870 \mathrm{~cm}^{-1}$ and at $1068 \mathrm{~cm}^{-1}$, which are associated with the absorption peaks of $\mathrm{Si}-$ $\mathrm{NO}$ and $\mathrm{Si}-\mathrm{O}$ bonds, respectively. ${ }^{31}$ After annealing, the absorption peak shifts toward $840 \mathrm{~cm}^{-1}$, which is characteristic of the $\mathrm{Si}-\mathrm{N}$ bond.

Ti 2p, Si 2p, and O 1s regions of the XPS spectra of the other composite film containing both titanium and silicon oxides on a silicon substrate, recorded when the sample is subjected to +10 and $-10 \mathrm{~V}$ external bias, are shown in Figure 4. Whereas, no difference can be detected in Ti $2 p$ upon reversal of the polarity of the bias, as much as $0.6 \mathrm{eV}$ difference can be induced in the $\mathrm{Si}$ $2 \mathrm{p}$ peak. Accordingly, the $\mathrm{O}$ 1s peak can be successfully fitted to two components: one exhibiting no shift that can be assigned as titanium oxide domains, and the other, which exhibits $0.6 \mathrm{eV}$ difference, to that of the silicon oxide domains. Hence, by controlling their charging capacity, we enforce domains to be separated and identified (charge contrast).

\section{CONCLUSIONS}

In this study, we demonstrate that by imposing a simple external voltage stress to the sample rod, while acquiring XPS data, we are able to control and measure the potential(s) developed as a result of charging in and on different domains. This simple charge-contrasting procedure introduces to XPS a capability to differentiate and determine the presence or absence of chemically/ electrically distinct domains in composite surface structures.

\section{ACKNOWLEDGMENT}

This work was partially supported by TUBA (Turkish Academy of Sciences) and by TUBITAK (The Scientific and Technological Research Council of Turkey) through the Grant 105M094.

Received for review July 26, 2006. Accepted October 10, 2006.

AC0613683 